\title{
Hubungan Tingkat Pengetahuan Mengenai Asma dengan Tingkat Kontrol Asma
}

\author{
Katerine, Irvan Medison, Erlina Rustam
}

\begin{abstract}
Abstrak
Kontrol gejala asma yang baik merupakan tujuan pengobatan bagi pasien asma. Pengobatan medikamentosa dan self management dibutuhkan untuk mencapai kontrol asma. Pengobatan medikamentosa dan self management yang baik akan tercapai jika pasien asma memiliki pengetahuan mengenai asma . Tujuan penelitian ini adalah untuk mengetahui hubungan antara tingkat pengetahuan asma dengan tingkat kontrol asma. Penelitian ini adalah penelitian cross sectional yang dilaksanakan pada bulan April hingga September 2013 di RSUP Dr. M.Djamil Padang dan RSUD Dr. Achmad Mochtar Bukittinggi. Subjek penelitian yang telah memenuhi kriteria inklusi akan diwawancara menggunakan lembar kuesioner data dasar, kuesioner AGKQ dan kuesioner ACT. Penelitian ini dilakukan pada 65 orang pasien asma yang datang ke Poliklinik Asma di RSUP Dr.M.Djamil Padang and RSUD Dr.Achmad Mochtar Bukittinggi selama bulan April hingga September 2013. Analisis statistik yang digunakan adalah uji chi square dan pengolahan data menggunakan software SPSS 15. Hasil penelitian menunjukkan dari 65 subjek penelitian, 19 (29,2\%) orang dengan asma tidak terkontrol memiliki pengetahuan yang rendah, $1(1,5 \%)$ orang dengan asma terkontrol sebagian dengan tingkat pengetahuan yang rendah dan 1 (1,5\%) orang pasien asma terkontrol total memiliki pengetahuan asma yang rendah. Pasien dengan pengetahuan asma rendah didapatkan 21 (32,3\%) orang dan pengetahuan asma tinggi $44(67,7 \%)$ orang. Berdasarkan uji chi square, terdapat hubungan yang bermakna antara tingkat pengetahuan asma dengan tingkat kontrol asma dengan nilai $p=<0,01(p<0,05)$.
\end{abstract}

Kata kunci: Asthma Control Test (ACT), Asthma General Knowledge Questionnaire (AGKQ), kontrol asma, pengetahuan asma.

\section{Abstract}

Good control of asthma symptomps is a goal for asthmatic patient. Medical treatment and self-management are needed to reach control of asthma. Good medical treatment and a good self-management will be achieved if the asthma patient have knowledge of asthma. The aim of this study is to find relation between asthma knowledge and asthma control. This study is a cross sectional that was conducted in April - September 2013 at asthma clinic Dr.M.Djamil Hospital, Padang and Dr.Achmad Mochtar Hospital, Bukittinggi. Subject who fulfilled the inclusion criteria was interviewed by using basic data information, asthma general knowledge questionnaire (AGKQ) and asthma control test (ACT). Used 65 asthmatic patients as sample that come to Ashma Polyclinic in RSUP Dr.M.Djamil Padang and RSUD Dr.Achmad Mochtar Bukittinggi during April until September 2013. The statistical analysis used chi square test and SPSS 15 for data processing. The results showed that from 65 subjects, $19(29,2 \%)$ subjects with uncontrolled asthma showed low level of asthma knowledge, $1(1,5 \%)$ subjects with partially controlled asthma showed low level of asthma knowledge, and $1(1,5 \%)$ subjects with controlled asthma showed low level of asthma knowledge. Patients with low level of asthma general knowledge was 21 samples $(32,3 \%)$ and high level of asthma general knowledge was 44 samples $(67,7 \%)$. Based on chi square test, there is significant association between asthma general knowledge with asthma control $p<0.01(<0.05)$.

Keywords: asthma control test(ACT), asthma general knowledge questionnaire(AGKQ), asthma control, asthma knowledge

Affiliasi penulis : Fakultas Kedokteran Universitas Andalas Korespondensi : Katerine, email: keket_10@yahoo.com Telp: Telp 081993838388

\section{PENDAHULUAN}

Asma adalah penyakit inflamasi saluran nafas yang dapat menyerang semua kelompok umur. Asma ditandai dengan serangan berulang sesak napas dan mengi, yang bervariasi setiap individunya dalam tingkat keparahan dan frekuensi. Asma dapat mempengaruhi kualitas hidup serta beban sosial ekonomi. Asma mempunyai tingkat fatalitas yang rendah namun kasusnya cukup banyak di negara dengan pendapatan menengah kebawah. WHO memperkirakan 235 juta penduduk dunia menderita asma dan jumlahnya diperkirakan akan terus bertambah. ${ }^{1}$ Apabila tidak dicegah dan ditangani dengan baik, maka diperkirakan akan terjadi peningkatan prevalensi di masa yang akan dating. ${ }^{2}$

Asma tidak dapat disembuhkan namun dapat dikontrol dengan manajemen yang tepat. ${ }^{1}$ Walaupun panduan penatalaksanaan asma sudah tersebar luas hampir di seluruh dunia serta berbagai obat baru terus dikembangkan namun penanganan asma di lapangan masih belum adekuat di negara berkembang maupun di negara maju. ${ }^{3}$

Data tentang tingkat kontrol asma pasien penderita asma di Indonesia belum diketahui secara pasti. Penelitian pendahuluan tingkat kontrol asma di Poliklinik Alergi Imunologi Klinik Departemen IImu Penyakit Dalam RSUPN Dr. Cipto Mangunkusumo Jakarta mendapatkan 64\% kasus tidak terkontrol, 28\% 
terkontrol baik, $8 \%$ tidak terkontrol sepenuhnya. ${ }^{4}$ Walau penyakit asma tidak dapat disembuhkan, hubungan baik pasien dan dokter dapat memberikan hasil optimal dalam mengontrol penyakit asma. Tujuan utama penatalaksanaan asma adalah untuk mencapai dan mempertahankan asma terkontrol, sehingga dapat dicegah timbulnya serangan saat malam dan siang hari serta pasien tetap dapat melakukan aktifitas fisik. Kontrol asma dikatakan dapat tercapai dengan didapatkannya penurunan frekuensi serangan asma, perbaikan inflamasi saluran napas, perbaikan aktivitas fisik dan fungsi paru. ${ }^{6}$

Seiring meningkatnya pengetahuan masyarakat tentang penyakit asma, didapatkan data perawatan penyakit asma menurun di rumah sakit Persahabatan Jakarta yang merupakan pusat rujukan nasional penyakit paru Indonesia, kunjungan pasien rawat jalan di Poli Asma RS Persahabatan tahun 1998 berjumlah 6167 pasien dan tahun 2006 berjumlah 3814 pasien, data ini berfluktuasi tetapi cenderung menurun, termasuk pasien rawat inap dan unit perawatan intensif. ${ }^{7}$ Kematian karena asma meningkat tahun delapan puluhan dan kemudian mengalami penurunan hingga tahun 2002. Hal ini menunjukkan bahwa penanganan yang cepat dan tepat dalam mengatasi serangan asma. ${ }^{8}$

Tingkat kontrol asma dapat dicapai dengan pengobatan medikamentosa serta self-management pasien asma yang baik, dimana salah satu faktor yang dapat mempengaruhi tingkat kontrol asma tersebut adalah pengetahuan tentang penyakit asma. Dengan adanya pengetahuan mengenai asma, pasien dapat mengenali dan melakukan self-management penyakit asma dengan efektif. ${ }^{9}$

Pengetahuan mengenai asma sangat penting dalam mencapai kontrol asma. Pasien dan keluarga pasien yang memahami penyakit asma dengan baik secara sadar akan menghindari faktor-faktor pencetus serangan, menggunakan obat secara benar dan berkonsultasi kepada dokter secara tepat. Selain memberikan motivasi kepada pasien, keberhasilan pengobatan juga ditentukan oleh pemberian obat obatan yang tepat dan diikuti pemberian pengetahuan tentang penyakit asma dan penatalaksanaanya. ${ }^{10}$

Pengetahuan pasien tentang penyakit asma merupakan salah satu faktor yang dapat mempengaruhi tingkat kontrol asma. Sehingga dengan mengetahui adanya hubungan antara tingkat pengetahuan mengenai asma dengan tingkat kontrol asma menjadi sangat penting untuk diketahui.

\section{METODE}

Desain yang akan digunakan dalam penelitian ini adalah observasional analitik dengan metode potong lintang (cross-sectional) yang dilaksanakan di Bagian Poliklinik Paru RSUP Dr.M.Djamil Padang dan RSUD Dr.Achmad Mochtar Bukittinggi. Waktu pelaksanaan adalah bulan April 2013 hingga September 2013. Populasi target dari penelitian ini adalah pasien penderita penyakit asma. Populasi terjangkau dari penelitian ini adalah pasien penyakit asma yang berobat ke Poliklinik Paru di RSUP M.Djamil Padang dan RSUD Dr.Achmad Mochtar Bukittinggi. Kriteria inklusi adalah responden yang telah didiagnosis asma oleh dokter spesialis paru dan responden bersedia dan mampu untuk menyelesaikan rangkaian pengambilan data. Kriteria eksklusi adalah responden dengan penyakit paru lain misalnya tuberkulosis paru, pneumonia, kanker paru, emfisema, dan lain lain.
Sampel dalam penelitian ini ditentukan dengan cara consecutive sampling.

Tingkat pengetahuan asma pada pasien dinilai melalui 31 pertanyaan di dalam kuesioner mengenai etiologi, patofisiologi, medikasi, perkiraan derajat asma serta manajemen gejala termasuk meminimalisasi faktor pencetus dan aktivitas fisik. Kuesioner yang digunakan adalah kuesioner Asthma General Knowledge Questionnaire (AGKQ), kuesioner ini pertama kali didemonstrasikan oleh Allen et al pada tahun 1998 di Amerika Serikat. Kuesioner ini memiliki konten dan validitas muka yang baik. AGKQ dapat diandalkan di dalam proses pengujian pengetahuan asma pada penelitian, sehingga kuesioner ini telah terbukti menjadi alat penelitian yang berharga untuk menentukan tingkat pengetahuan asma baik pada intervensi pendidikan dan keadaan klinis. Hasil skor didapatkan dari skor persentase dari jawaban yang benar. ${ }^{11}$

Pada penelitian ini tingkat kontrol asma dikategorikan menjadi dua kategori :

a. Rendah bila jawaban benar $<60 \%$

b. Tinggi bila jawaban benar $\geq 60 \%$

Tingkat kontrol asma dinilai melalui kuesioner ACT (Asthma Control Test). Kuesioner ini berisi 5 pertanyaan dan masing masing pertanyaan mempunyai skor 1 sampai 5 , sehingga nilai terendah ACT adalah 5 dan tertinggi adalah 25 . $^{12}$

Pada penelitian ini tingkat kontrol asma dikategorikan menjadi 3 kategori :

a. Tidak terkontrol : skor $<19$

b. Terkontrol sebagian: skor $20-24$

c. Terkontrol total : skor 25

Lembar kuesioner terdiri dari lembar kuesioner data dasar, lembar kuesioner ACT, dan lembar kuesioner AGKQ. Lembar kuesioner data dasar berisi tentang karakteristik subjek penelitian yaitu jenis kelamin, usia, tingkat pendidikan, tinggi badan, berat badan, IMT, dan riwayat merokok.

Lembar kertas kuesioner ACT (Asthma Control Test) dan lembar kertas kuesioner AGKQ yang telah diterjamahkan ke dalam bahasa Indonesia. Sumber data yang akan digunakan pada penelitian ini adalah sumber data primer. Data primer diperoleh dari subjek pasien asma yang datang berobat ke Poliklinik Paru RSUP Dr. M. Djamil Padang dan RSUD Dr. Achmad Mochtar Bukittinggi.

Penandatanganan informed consent dan wawancara untuk pengisian kuesioner dilakukan pada pasien yang telah didiagnosis asma oleh dokter spesialis paru di poliklinik paru RSUP Dr. M.Djamil Padang dan RSUD Dr. Achmad Mochtar

Data yang terkumpul dari penelitian ini akan dicatat dan diolah lebih lanjut untuk dilakukan uji statistik dengan menggunakan program SPSS (Statistical Package for Social Sciences) for Windows versi 15 . Analisis yang dilakukan secara univariat dan bivariat. Analisis univariat akan menyajikan data dalam bentuk tabel distribusi frekuensi sehingga terlihat gambaran deskriptif dari variabel yang diteliti. Analisis bivariat dilakukan dengan uji kemaknaan Chi Squre untuk melihat hubungan antara dua variabel yaitu variabel bebas dan terikat, bila tidak memenuhi syarat digunakan uji Kolmogorov-Smirnov. Jika terdapat perbedaan bermakna $(p<0,05)$ dan tidak ada perbedaan bermakna $(p>0,05)$.

\section{HASIL}

\section{Data dan Karakteristik Sampel}


Data subjek penelitian sebanyak 65 orang dan tidak ada responden yang drop out. Pasien asma pada penelitian ini sebagian besar berjenis kelamin perempuan $49(75,4 \%)$ dan laki laki sebanyak 16 $(24,6 \%)$ dengan usia rata rata 53,22 tahun (SD 14,67).

Pasien asma dengan lulusan SD sebanyak 21 orang $(32,3 \%)$, SLTA 15 orang $(23,1 \%)$, perguruan tinggi 14 orang $(21,5 \%)$, dan 5 orang $(7,7 \%)$ tidak bersekolah.

Pasien asma yang tidak merokok sebanyak 48 orang $(73,8 \%)$, pernah merokok 15 orang $(23,1 \%)$, dan 2 orang $(3,1 \%)$ merokok. Berat badan pasien rata rata $53,8 \mathrm{~kg}(S D$ 10,36) dan tinggi badan rata-rata pasien 157,3 cm (SD 6,60). Pasien asma dengan indeks massa tubuh normal sebanyak 41 orang $(63,1 \%)$, berat badan kurang dan pre obesitas masing masing 11 orang $(16,9 \%)$ dan 2 orang $(3,1 \%)$ dengan obesitas.

\section{Skor ACT (Asthma Control Test)}

Skor ACT tertinggi yang didapatkan pada penelitian ini adalah skor sempurna yaitu 25 dan skor terendah yang didapatkan 6 . Rata rata skor ACT yang didapatkan pada penelitian ini yaitu 16,43 (SD 6,16)

\section{Skor AGKQ (Asthma General Knowledge Questionnaire)}

Skor tingkat pengetahuan asma berdasarkan AGKQ didapatkan nilai tertinggi yaitu $90 \%$ dan nilai terendah yaitu $32 \%$, dengan rata rata skor yang didapatkan adalah $67,28 \%$ (12,56 SD).

\section{Prevalens Tingkat Kontrol Asma}

Tabel 1. Tingkat Kontrol Asma Subjek Penelitian

\begin{tabular}{lcc}
\hline $\begin{array}{l}\text { Tingkat Kontrol } \\
\text { Asma }\end{array}$ & $\mathrm{N}$ & $\%$ \\
\hline Tidak Terkontrol & 36 & $55,4 \%$ \\
Terkontrol Sebagian & 18 & $27,7 \%$ \\
Terkontrol Total & 11 & $16,9 \%$ \\
\hline
\end{tabular}

Dari 65 orang subjek penelitian, didapatkan pasien asma tidak terkontrol sebanyak 36 orang $(55,4 \%)$, terkontrol sebagian 18 orang $(27,7 \%)$, dan terkontrol total 11 orang $(16,9 \%)$.

\section{Prevalens Tingkat Pengetahuan Asma}

Tabel 2. Tingkat Pengetahuan Asma Subjek Penelitian

\begin{tabular}{lcc}
\hline $\begin{array}{l}\text { Tingkat } \\
\text { Pengetahuan } \\
\text { Asma }\end{array}$ & $\mathrm{N}$ & $\%$ \\
\hline Rendah & 21 & $32,3 \%$ \\
Tinggi & 44 & $67,7 \%$ \\
\hline
\end{tabular}

Hubungan Tingkat Kontrol Asma dengan Tingkat Pengetahuan Asma

Tabel 3. Hubungan Tingkat Kontrol Asma dengan Tingkat Pengetahuan Asma pada Asma Tidak Terkontrol

\begin{tabular}{|c|c|c|c|}
\hline & & \multicolumn{2}{|c|}{$\begin{array}{c}\text { Tingkat Kontrol } \\
\text { Asma } \\
\text { Asma Tidak } \\
\text { Terkontrol } \\
\end{array}$} \\
\hline & & $\mathrm{n}$ & $\%$ \\
\hline $\begin{array}{c}\text { Tingkat } \\
\text { Pengetahuan } \\
\text { Asma }\end{array}$ & $\begin{array}{c}\text { Rendah } \\
\text { Tinggi }\end{array}$ & $\begin{array}{l}19 \\
17\end{array}$ & $\begin{array}{l}29,2 \% \\
26,2 \%\end{array}$ \\
\hline Total & & 36 & $55,4 \%$ \\
\hline
\end{tabular}

Tabel 4. Hubungan Tingkat Kontrol Asma dengan Tingkat Pengetahuan Asma pada Asma Terkontrol Sebagian

\begin{tabular}{|c|c|c|c|}
\hline & & \multicolumn{2}{|c|}{$\begin{array}{c}\text { Tingkat Kontrol } \\
\text { Asma } \\
\text { Asma Terkontrol } \\
\text { Sebagian } \\
\end{array}$} \\
\hline & & $\mathrm{n}$ & $\%$ \\
\hline $\begin{array}{c}\text { Tingkat } \\
\text { Pengetahuan } \\
\text { Asma }\end{array}$ & $\begin{array}{l}\text { Rendah } \\
\text { Tinggi }\end{array}$ & $\begin{array}{c}1 \\
17\end{array}$ & $\begin{array}{r}1,5 \% \\
26,2 \%\end{array}$ \\
\hline Total & & 18 & $27,7 \%$ \\
\hline
\end{tabular}

Tabel 5. Hubungan Tingkat Kontrol Asma dengan Tingkat Pengetahuan Asma pada Asma Terkontrol Sebagian

\begin{tabular}{|c|c|c|c|}
\hline & & \multicolumn{2}{|c|}{$\begin{array}{c}\text { Tingkat Kontrol } \\
\text { Asma } \\
\begin{array}{c}\text { Asma Terkontrol } \\
\text { Total }\end{array}\end{array}$} \\
\hline & & $\mathrm{n}$ & $\%$ \\
\hline $\begin{array}{c}\text { Tingkat } \\
\text { Pengetahuan } \\
\text { Asma }\end{array}$ & $\begin{array}{l}\text { Rendah } \\
\text { Tinggi }\end{array}$ & $\begin{array}{c}1 \\
10\end{array}$ & $\begin{array}{c}1,5 \% \\
15,4 \%\end{array}$ \\
\hline Total & & 11 & $16,9 \%$ \\
\hline
\end{tabular}

Pasien asma tidak terkontrol yang memiliki pengetahuan rendah sebanyak 19 orang $(90,5 \%)$ dan dengan pengetahuan tinggi 17 orang $(38,6 \%)$. Pasien asma terkontrol sebagian dengan pengetahuan rendah sebanyak 1 orang $(4,8 \%)$ dan dengan pengetahuan tinggi sebanyak 17 orang (38,6\%). Pasien asma terkontrol total dengan pengetahuan rendah sebanyak 1 orang $(4,8 \%)$ dan dengan pengetahuan tinggi sebanyak 10 orang $(22,7 \%)$.

Dapat disimpulkan terdapat perbedaan proporsi tingkat pengetahuan pada asma tidak terkontrol, didapatkan $90,5 \%$ pasien asma tidak terkontrol memiliki pengetahuan asma yang rendah 
dan $38,6 \%$ dengan pengetahuan asma yang tinggi.

Dalam penelitian ini didapatkan nilai significancy-nya sebesar 0,0001 , nilai $p<0,05$ maka terdapat hubungan yang bermakna antara tingkat pengetahuan asma dengan tingkat kontrol asma.

\section{PEMBAHASAN}

\section{Tingkat Pengetahuan Asma}

Tingkat pengetahuan asma pada penelitian ini dinilai berdasarkan kuesioner $A G K Q$, dimana rata rata skor $A G K Q$ yang didapatkan dari penelitian ini adalah $67,28 \%$. Sehingga dapat disimpulkan bahwa sebagian besar pasien asma pada penelitian ini memiliki tingkat pengetahuan asma yang tinggi. Sebaliknya penelitian oleh Wardani didapatkan skor rata rata tingkat pengetahuan melalui kuesioner AGKQ sebanyak 58,59\%, dengan kesimpulan bahwa sebagian besar pasien asma dewasa memiliki pengetahuan asma yang rendah. ${ }^{13}$

Dari 65 pasien asma didapatkan sebanyak 21 orang $(32,3 \%)$ dengan tingkat pengetahuan asma yang rendah dan 44 orang $(67,7 \%)$ dengan tingkat pengetahuan asma yang tinggi. Hasil ini tidak sama dengan penelitian sebelumnya oleh Edisworo yang mendapatkan pasien asma dengan pengetahuan asma tinggi lebih sedikit yaitu 49 orang $(45,8 \%)$ dan pasien asma dengan tingkat pengetahuan rendah sebanyak 58 orang $(54,2 \%){ }^{4}$ Hal serupa juga ditemukan pada penelitian yang dilakukan oleh Wardani didapatkan sebanyak 14 orang (46,67\%) dengan tingkat pengetahuan asma tinggi dan 16 orang $(53,3 \%)$ dengan tingkat pengetahuan asma rendah. ${ }^{13}$ Hal ini mungkin berkaitan dengan jumlah sampel yang kecil sehingga menghasilkan persentase yang lebih besar dan banyaknya faktor lain yang mempengaruhi tingkat pengetahuan asma yang tidak di ketahui dalam penelitian ini.

\section{Tingkat Kontrol Asma}

Tingkat kontrol asma pada penelitian ini didapat berdasarkan hasil kuesioner ACT. Skor ACT tertinggi pada penelitian ini adalah 25 dengan skor terendah 6 dan rata rata skor yang didapatkan adalah 16,43 sehingga dapat disimpulkan sebagian besar pasien asma pada penelitian ini memiliki asma yang tidak terkontrol. Begitu juga penelitian sebelumnya yang dilakukan oleh Sabri di poliklinik asma RSUP Dr. M.Djamil dimana didapatkan skor ACT rata rata pada awal penelitian sebesar 14,7 yang juga menyimpulkan sebagian besar pasien asma memiliki tingkatan asma tidak terkontrol. ${ }^{15}$

Berdasarkan hasil pemeriksaan ACT didapatkan 36 orang $(55,4 \%)$ dengan asma tidak terkontrol, 18 orang $(27,7 \%)$ dengan asma terkontrol sebagian, dan 11 orang dengan asma terkontrol total $(16,9 \%)$. Bachtiar melakukan penelitian yang juga menggunakan ACT untuk menilai tingkat kontrol asma dimana didapatkan hasil yang hampir serupa yaitu 230 orang $(66,9 \%)$ dengan asma tidak terkontrol, 113 orang $(33,0 \%)$ asma terkontrol sebagian, dan hanya 1 orang $(0,1 \%)$ dengan asma terkontrol total. ${ }^{16}$

Pada penelitian yang dilakukan oleh Atmoko mengenai prevalens asma tidak terkontrol di Poliklinik Asma di RS Persahabatan juga memliki hasil yang hampir serupa, dari 107 pasien asma didapatkan 81 orang $(75,7 \%)$ dengan asma tidak terkontrol dan hanya 26 orang $(24,3 \%)$ dengan asma yang terkontrol. $^{17}$

\section{Hubungan Tingkat Pengetahuan Asma dengan Tingkat Kontrol Asma}

Dalam penelitian ini didapatkan perbedaan proporsi asma tidak terkontrol yang memiliki pengetahuan asma rendah dan tinggi. Sehingga dapat disimpulkan terdapat hubungan antara tingkat pengetahuan asma dengan tingkat kontrol asma ( $p<$ $0,05)$ dengan nilai $p$ yang didapat yaitu 0,0001 . Hasil ini sesuai dengan teori sebelumnya berdasarkan studi Cicak $B$ et al dengan hasil penelitian $(p<0,0001)$ yang menyimpulkan bahwa terdapat hubungan tingkat pengetahuan asma dengan tingkat kontrol asma pasien. ${ }^{18}$ Begitu juga penelitian yang dilakukan oleh Wardani di RSUD Dr. Moewardi didapatkan tingkat pengetahuan asma dengan tingkat kontrol asma memiliki kemaknaan 0,041, yang menunjukkan adanya hubungan yang bermakna nilai $p<0,05 .^{13}$

Namun hal ini tidak sesuai dengan penelitian sebelumnya yang dilakukan oleh Edisworo dimana dari hasil pengujian data tidak membuktikan adanya hubungan yang bermakna secara statistic antara tingkat pengetahuan asma terhadap tingkat kontrol asma, didapatkan nilai $p=0,189 .^{14}$

Berdasarkan data kuesioner AGKQ, didapatkan pada penelitian ini bahwa pernyataan yang paling banyak dijawab salah yaitu mengenai kematian akibat asma yang dapat terjadi sedemikian cepat sehingga tidak sempat untuk memulai pengobatan.

Sedangkan pernyataan yang dijawab benar oleh semua responden yaitu mengenai mengurangi serangan asma dengan berusaha mencari tahu dan menghindari penyebab pemicu serangan asma dan pernyataan bahwa asma jika sudah terkontrol dengan obat maka akan sulit timbulnya serangan asma kembali. Hal ini membuktikan sudah meningkatnya pengetahuan pasien asma untuk mencapai asma yang terkontrol atau bebas dari gejala asma dengan menghindari faktor pencetus dan terapi medikamentosa yang tepat. Hal ini sesuai dengan penelitian yang dilakukan oleh Allen RM et al, dimana untuk mencapai kontrol asma yang baik sangat diperlukannya self-management dan terapi medikamentosa yang tepat. ${ }^{19}$

\section{KESIMPULAN}

Dari hasil penelitian dan pembahasan yang telah diuraikan dapat disimpulkan:

1. Sebagian besar pasien asma pada penelitian ini dengan jenis kelamin perempuan. IMT terbanyak normal dan riwayat merokok terbanyak adalah tidak pernah merokok.

2. Sebagian besar pasien asma pada penelitian ini memiliki tingkat pengetahuan mengenai asma yang tinggi.

3. Sebagian besar pasien asma pada penelitian ini memiliki tingkat kontrol asma yang tidak terkontrol.

4. Terdapat perbedaan proporsi asma tidak terkontrol pada pengetahuan asma tinggi dan rendah, sehingga dapat disimpulkan terdapat hubungan yang bermakna antara tingkat pengetahuan dengan tingkat kontrol asma.

\section{DAFTAR PUSTAKA}

1. World Health Organization (WHO). 2013. Asthma.

http://www.who.int/respiratory/asthma/definiti on/en/index.html diakses pada 10 April 2013

2. Departemen Kesehatan R.I. 2009. Pedoman Pengendalian Penyakit Asma. Jakarta: Departemen Kesehatan Republik Indonesia. 
3. National Education and Prevention Program (NAEPP). 2007. Guidelines for the diagnosis and management of asthma. United States: National Heart, Lung and Blood Institute (NHLBI) of National Institute of health (NHI) Publication.

4. Rengganis, Indri.2008. Diagnosis dan Tatalaksana Asma Bronkial dalam Majalah Kedokteran Indonesia volum:58. Pp. 444-451

5. Global Initiative for Asthma. Global strategy for asthma management and prevention update 2012. (cited on February $12^{\text {th }} 2013$ ). Available from: URL: http://www.ginasthma.org/Guidelines/guidelin es-resources.htm

6. Lundback B, Ronmark E, Linberg A, Jonsson $A C$, Larsson LG, Petavy $F$, et.al.Control of mild to moderate asthma over 1 -year with the combination of salmeterol and fluticasone propionate. Respir Med 2006; 100:2-10

7. Ratnawati. Epidemiologi Asma. J Respir Indonesia : Volum: 31, Nomor: 4, Oktober $2011 ; 174$

8. Global Initiative for Asthma. Global strategy for asthma management dan prevention. Update 2008.p.22-9

9. Redman, Barbara Klung. 2003 Measurement Tools in Patient Education. New York:Springer Publishing Company. Pp. 160 163.

10. Eder, Waltroud, Markus J. Ege, Erika M. 2006. The Asthma Epidemic. N Engl J Med $355 ; 21$.

11. Allen RM, Jones MP. The validity and reliability of an asthma knowledge questionnaire used in the evaluation of a group asthma education self-management program for adults with asthma. J Asthma. 1998;35(7):537-45.
12. Thomas M, Kay S, Pike J, Williams A, Rosenzweig JR, Hilyer EV, Price D. The Asthma Control Test (ACT) as a predictor of GINA guideline defined asthma control: analysis of a multinational cross-sectional survey. Prim Care Respir J 2009;18:41-9.

13. Wardani, VK. 2012. "Hubungan antara Tingkat Pengetahuan Umum Asma Pasien dengan Tingkat Kontrol Asma di RSUD Dr.Moewardi". Skripsi. Universitas Muhammadiyah. Surakarta.

14. Edisworo, M.W. 2009. "Hubungan antara Tingkat Pengetahuan Umum Asma dengan Tingkat Kontrol Asma Pasien di Poliklinik Asma Rumah Sakit Persahabatan Jakarta". Skripsi. Universitas Indonesia. Jakarta

15. Yessy, SS. 2010. "Penggunaan Asthma Control Test (ACT) Pada Penderita Asma di Poliklinik Paru RS Dr. M.Djamil Padang". Tesis. Universitas Andalas. Padang.

16. Bachtiar, Deva. 2010. "Proporsi Asma Terkontrol Berdasarkan Asthma Control Test (ACT) di Poli Asma RS Persahabatan Jakarta Periode Mei - Juli 2009". Tesis. Universitas Indonesia. Jakarta.

17. Atmoko $\mathrm{W}$, Khairina $\mathrm{H}$, Faisal $\mathrm{P}$, Bobian $\mathrm{ET}$, Adisworo MW, Yunus F. Prevalens asma tidak terkontrol dan faktor faktor yang berhubungan dengan tingkat kontrol asma di poliklinik asma RS Persahabatan Jakarta. J Respir Indo. 2011;31: 53-60

18. Cicak B, Verona E, Mihtov-Stefanovic I. An individualized approach in the education of asthmatic children. Acta Clin Croat 2008; 47(4):231-8

19. Allen RM, Jones MP, Oldenberg B. Randomised trial of an asthma selfmanagement programme for adults. Thorax. 1995;50: 731-738. 